\title{
How Technology Import Improves the Enterprise's Innovation Capacity: The Mediating Role of Absorptive Capacity
}

\author{
Zheng-qun $\mathrm{ZHAN}^{1, \mathrm{a}}$, Min LI, b, ${ }^{1}$ and Yan $\mathrm{XIE}^{1}$ \\ ${ }^{1}$ School of Economics and Commerce, South China University of Technology, \\ P.R. China, 510004 \\ a zhanzq@scut.edu.cn; ${ }^{b}$ lim@scut.edu.cn \\ ${ }^{*}$ Corresponding author
}

Keywords: Technology import, Innovation capacity, Absorptive capacity, High-tech industry.

\begin{abstract}
Technology plays a key role in determining productivity and economy development in a country. The process of enterprises' innovation can be seen as a process of knowledge management including the process of knowledge attainment; acquisition and converting and integrating into new knowledge. This research analyzes the influence factors and mechanism of the independent innovation of high tech enterprises in the year 1995-2013. The result shows that the technology import has a significant positive effect on the innovation capacity of enterprises. And the absorptive capacity, represented by the research outlay input and research staff input, has a significant positive effect on the innovation capacity of enterprises. Furthermore, the effect of technology import on the independent research capacity of high-tech enterprises is significantly positively affected by their absorptive capacity.
\end{abstract}

\section{Introduction}

Technology plays a key role in determining productivity and economy development in a country. The process of enterprises' innovation can be seen as a process of knowledge management including the process of knowledge attainment; acquisition and converting and integrating into new knowledge[1-4]. In order to improve the innovation capacity, the enterprise can generally upgrade from two channels: first of all, the introduction of new technology, and secondly, to carry out technical research and development. There are two questions need to be answer: How technology import Influence the enterprise's innovation capacity, and what effect the absorptive capacity contribute to above process? This research analyzes the influence factors and mechanism of the innovation of high tech enterprises based on the data of Chinese technology import during year 1995-2013.

\section{Theoretical Background}

The first point holds that technology import may improve the innovation capacity of enterprises. Lin $(1997,2006)$ suggests when the cost of technology import is lower than that of research, according to the Theory of Comparative Advantage [5], that underdeveloped countries and areas introduce technology and realize faster technology upgrade than developed countries will not fall into the trap of producing products with low technology level forever, but will acquire faster speed of economic development and the late-development advantage. Zhu (2006) et al.'s research indicates the purchase of tangible technology from state-owned 
enterprises has significant positive effects on the promotion of their labor productivity and technology, while the positive effects strongly depend on the scientific human resources of state-owned enterprises [6]. The more interesting thing is that they haven't found that other domestic funded enterprises' introduced technology has such significant effects on their productivity. Liu (2011) et al. hold an empirical analysis of the effect of technology import on the technology innovation capacity of China's enterprises, using the 2001-2008 data of China's interprovincial large and mediumenterprises. The outcome shows China's technology import has a positive effect on the innovation capacity of enterprises, but the effect will gradually undermine with the improvement of areas' innovation capacity. At the same time, the positive effect of technology import on the development and sale of the new product surpasses the positive effect of it on the technology research capacity of enterprises $[7,8]$.

The other scholars argue that merely depending on technology import easily results into the import trap, resulting in the lack of inner innovation stimulus, which constrains the development of innovation capacity. In 1990, research indicated that developing countries had been gradually changing their roles during the process of technology import. They had not only introduced technology purely, but also arouse their national technology innovation capacity. As for the technology introduced, they focused on the assimilation of them more. Some domestic academics believe that technology import may have bad effects on China's innovation and research project, for it may disturbs China's technology innovation to some extents, affecting the orderly process of China's enhancement of innovation capacity and technology innovation progression. Ma Jun, the previous high-tech director of the national science board and responsible for the 863 project, holds the view that China's large and medium enterprises have spent the most of the financial and material resources of the country. It has already cost up to several hundred billion for enterprises such as energy, mining and power to make some technology reconstruction. If they still continue to emphasize on technology import rather than on technology innovation, do China's large state-owned enterprises still have to enhance the technology ability by buying other countries' technology in 20 years? The system of technology innovation and the innovation team are more important than technology import to enterprises.

What's more, some other scholars believe there is no need to look at the two parts in isolation while it is better to synthesize them. For example, Huang (2005) argued that there exists an equilibrium between technology import and innovation, which requires taking both the cost factor and the market factor into account, exploiting these two ways rationally. What on earth the effect of technology import on enterprise's innovation capacity and how it affects the innovation capacity, are the main questions discussed in this article. Based on the statistical data of technology import in high- tech enterprises in China from 1995 to 2012, this research discusses four kind of effects of technology import on enterprise's innovation performance, and analyzes the process of the effects of technology import on the innovation performance of high- tech enterprises.

\section{Research Hypothesis}

\section{Technology Import and Innovation}

Theoretically, directly introducing technology is supposed to have more direct positive effects on the innovation performance of enterprises than introducing products does on it, maybe because the introduced technology could be directly used without the intervening link of 
assimilation, decreasing the transformation cost. But the outcome of empirical analysis overthrows the hypothesis. Wang (2011) et al.'s research has the similar outcome. They use the data of license of patents in 186 domestic native enterprises from 2000 to 2003 to do an empirical analysis, the outcome of which indicates that the hypothesis that the import of international license of patents may improve the international innovation capacity of enterprises is not supported. The absorptive capacity of enterprises and the scale of enterprises have positive effects on their technology import and enhance their innovation capacity, while the effects of regional innovation systems and the industry characteristics of enterprises are not significant, but they have no explanation to it.

Song (2011) et al. find that in the course of exploiting external technology resources, the enterprises' technology strategy, studying culture and the process of technology studying have very important active effects on the enhancement of technology capacity, while generally external technology acquirement has very limited effect on the enhancement of technology capacity. Also, they point out that native enterprises should focus on internal technology studying and independent research but not external technology acquirement.

Therefore, it is obviously that the influence of international technology import on the innovation is still uncertain. There are several hypothesis as follows:

Hypothesis 1a:International technology import has a significant positive relationship with the innovation capacity of high-tech enterprises.

Hypothesis $1 \mathrm{~b}$ : International technology import has a significant negative relationship with the innovation capacity of high- tech enterprises.

In this research, international technology import has three main forms: technology import, technology consultation, direct investment (joint venture cooperation or facilitate purchase).

\section{Absorptive Capacity and Innovation Capacity}

The absorptive capacity reflects a serious of organizational convention and the process of acquiring, assimilating, transforming and exploiting external knowledge by enterprises. The absorptive capacity of enterprises has a profound influence on their innovation capacity. According to the outcome from current researches, academics consistently believe that the absorptive capacity of enterprises has a significant positive effect on innovation capacity [9-11]. Wang (2009) et al. indicate that enterprises' reserve of knowledge and experience plays a vital role in their realizing new knowledge. But in the step of assimilating the introduced external technology, the absorptive capacity plays a very key mediating role, responsible for transforming the original external technology into organizational self-technology. Thus, essentially, enterprises with stronger absorptive capacity are easier to make the following three points: the first, they are good at realizing which kind of knowledge in the market can be mimed, exploited or improved by them, and they can explain the acquired technology information; the second, they have the capacity to develop new technology and acquire the substitute use of technology or integrate the new technology into the original one; the third, they can directly make adjustments, improvements or innovation in the industrial arts during the production.

Apparently, the absorptive capacity has a significant positive effect on the innovation capacity of enterprises. Therefore, this article has several hypothesis as follows:

Hypothesis 2a: the research outlay input has a significant positive relationship with the independent research capacity of high-tech enterprises. 
Hypothesis $2 \mathrm{~b}$ : the research staff input has a significant positive relationship with the independent research capacity of high-tech enterprises.

Research shows that, based on China's characteristics of resources and technology foundation, the model of "import-assimilation-innovation" has become the common model of technology innovation in manufacture industry in China [12,13]. The spillover effect of technology import significantly enhances the technology innovation capacity of China, while the strength of research and the system of the international technology spillover of the import and export of intermediate products have a significant positive effect towards China's enterprises [14]. Thus, we put forward the following hypothesis:

Hypothesis 3: The effect of technology import on the independent research capacity of high-tech enterprises is affected by their absorptive capacity.

\section{Research Design and Empirical Analysis Result}

This research does an empirical analysis of all the hypothesis, based on established multiple regression models. In the selection of variables in the models, this research sets the performance of innovation of high-tech enterprises as the dependent variable. Patent, regarded as the output of innovation, is usually used to measure the strength of the innovation capacity. We continue to use this kind of measure standard, using the aggregate of three kinds of patents (invention y1, practical new type y2 and exterior design y3) to represent the innovation capacity.

According to the comparative analysis of other academics researches, this research regards that technology import can be divided into two forms, the pure technology import and the technical product import. The pure technology imports(x1) can be divided into the following three kinds: technology import(x2), technology consultancy and cooperation(x3), and joint venture cooperation and key equipment purchase $(\mathrm{x} 4)$. The technical product import can be represented by the indicator of the amount of imports of high-tech products.

As for the measure of the absorptive capacity, scholars have taken different kinds of methods. Tsai (2006) et al. regard that the absorptive capacity of operating departments depends on their strength of research to a great extent, while the strength of research is measured on the ratio of research outlay to sales volume. Major scholars consider that the factor of human resources is the most important factor of the absorptive capacity. Lai (2011) argue that domestic research input and human resources have a relationship of long-run equilibrium with China's total factor productivity. We synthesize these two points, using the two factors of research outlay input and research staff input to measure the absorptive capacity. We use the research outlay(billions)(z1) and the research staff full work time (ten thousands hours) (z2) to be the indicators of the absorptive capacity.

Therefore, the research models are shown in the following equation 1-6:

The first is the main effect model of the pure technology import and the innovation capacity: $y=a_{1} x_{2}+a_{2} x_{3}+a_{3} x_{4}+\varepsilon_{1}$.

(Equation 1)

The second is the main effect model of the high-tech products import and the innovation capacity.

$$
y=a_{4} x_{5}+\varepsilon_{2} .
$$

The third is the main effect model of the influence of the absorptive capacity on the innovation capacity.

$$
y=b_{1} z_{1}+b_{2} z_{2}+\varepsilon_{3} .
$$

(Equation 3) 
The fourth is the effect model of the comprehensive influence of the technology import and the absorptive capacity on the innovation capacity.

$$
y=a_{1} x_{2}+a_{2} x_{3}+a_{3} x_{4}+a_{5} x_{5}+b_{1} z_{1}+b_{2} z_{2}+\varepsilon_{4} \text {. }
$$

Finally, the research investigates the interaction between the absorptive capacity and the technology import.

$$
\begin{array}{ll}
y=a_{1} x_{2}+a_{2} x_{3}+a_{3} x_{4}+a_{5} x_{5}+b_{1} z_{1}+c_{1} x_{2} z_{1}+c_{2} x_{3} z_{1}+c_{3} x_{4} z_{1}+c_{4} x_{5} z_{1}+\varepsilon_{5} . & \text { (Equation 5) } \\
y=a_{1} x_{2}+a_{2} x_{3}+a_{3} x_{4}+a_{5} x_{5}+b_{1} z_{2}+c_{1} x_{2} z_{2}+c_{2} x_{3} z_{2}+c_{3} x_{4} z_{2}+c_{4} x_{5} z_{2}+\varepsilon_{6} . & \text { (Equation 6) }
\end{array}
$$

\section{Data Descriptive Analysis}

In order to get knowledge of our country's development condition of high-tech industry, the researchers comprehensively reorganize the data from <China Statistical Yearbook> (2000-2013), <China Statistical Yearbook of science and technology > (2000-2013) and $<$ China high tech statistical yearbook> (2000-2013).

According to the collected data with a time span of 18 years, from 1995 to the late 2012, the scale of technology import has increased in multiples. The technology import has increased from 29.16 billion yuan to 393.9 billion yuan, which grows more than tenfold. The purchase of foreign high-tech products increases from 218.27billions yuan to 5068.64 billion yuan, growing more than twenty fold. The main four kinds of ways of technology import: patents, proprietary technology license, transfer and purchase of complete sets of equipment and key equipment have increased most swiftly, as shown in the figure 1 .

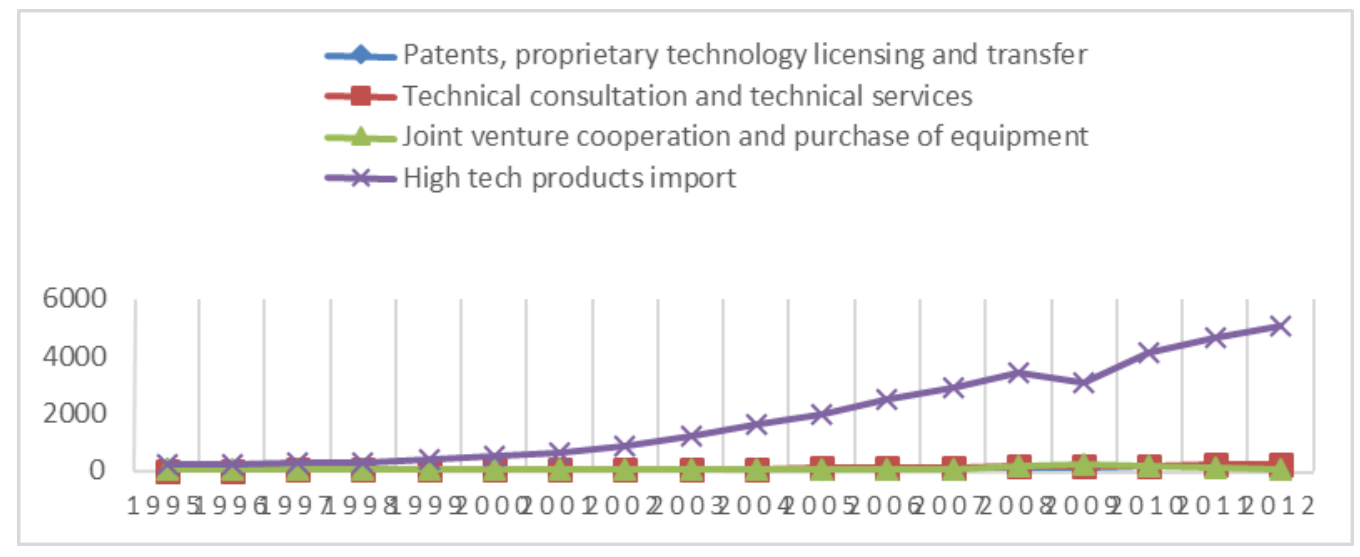

Figure 1. 1995-2012 Chinese technology import development

As shown in figure 1, four kind of technology import has been increasing, but each has a different tendency. The joint venture cooperation production has not been the main way of investment after 2000, after a several years of growth initially, while patent, proprietary technology license and transfer has kept the tendency of growing.

To explore the relationship among the variables, this research use Stata12.0 to analyze the data, based on the method of GMM. Considering there is a certain time lag among the technology import, research input and the innovation outcome, this research uses the method of one-period lag to analyze. The outcome is shown in the next part. At the same time, to analyze more conveniently and avoid that the outcome may be affected by over-dispersed data, the data was take the logarithm. According to the data from the table 1, the data contributes to the normal distribution.

According to the table 1 , there exists relative high interrelations among the majority of indicators, bur actually, indicators have no such significance in the sense of practice other than $\mathrm{x} 1, \mathrm{x} 2, \mathrm{x} 3$, and $\mathrm{x} 4$, while the last four indicators exist a linear relationship in the practice. 
Perhaps the high-related relationship means the problem of multicollinearity. Therefore, to get meaningful conclusions, the method of Ridge regression is used to analyze.

Table 1. Correlation matrix

\begin{tabular}{l|c|c|c|c|c|c|c|c|c|c}
\hline & Mean & S.E. & LnX1 & LnX2 & LnX3 & LnX4 & LnX5 & LnZ1 & LnZ2 & LnY1 \\
\hline LnX1 & 2.0256 & .11648 & 1 & & & & & & & \\
\hline LnX2 & 3.3317 & .34705 & $.962^{* *}$ & 1 & & & & & & \\
\hline LnX3 & 3.2004 & .45084 & $.914^{* *}$ & $.977^{* *}$ & 1 & & & & & \\
\hline LnX4 & 3.5626 & .21670 & $.761^{* *}$ & $.619^{* *}$ & $.552^{*}$ & 1 & & & & \\
\hline LnX5 & 7.0353 & .26729 & $.973^{* *}$ & $.981^{* *}$ & $.949^{* *}$ & $.627^{* *}$ & 1 & & & \\
\hline LnZ1 & 5.3964 & .31340 & $.958^{* *}$ & $.984^{* *}$ & $.965^{* *}$ & $.604^{* *}$ & $.986^{* *}$ & 1 & & \\
\hline LnZ2 & 4.8788 & .11532 & $.950^{* *}$ & $.905^{* *}$ & $.857^{* *}$ & $.654^{* *}$ & $.941^{* *}$ & $.937^{* *}$ & 1 & \\
\hline LnY & 12.5371 & .17125 & $.894^{* *}$ & $.931^{* *}$ & $.917^{* *}$ & $.504^{*}$ & $.945^{* *}$ & $.924^{* *}$ & $.826^{* *}$ & 1 \\
\hline
\end{tabular}

*. Significant at $\mathrm{P} \leq 0.05$;**. Significant at $\mathrm{P} \leq 0.01$; ***. Significant at $\mathrm{P} \leq 0.001$.

\section{Empirical Analysis Result}

Model 1-4 test the direct influence of technology imports on the innovation capacity of high-tech enterprises. The outcome is shown in table 2.

Table 2. Ridge regression result(I) (Y=innovation capacity)

\begin{tabular}{l|l|l|l|l}
\hline & M1 & M2 & M3 & M4 \\
\hline LnX1 & $0.846 *(6.141)$ & & $0.922 * * *(9.239)$ & \\
\hline LnX2 & & $0.343 * * *(209.234)$ & & $0.262 * * *(214.499)$ \\
\hline LnX3 & & $0.308 * * *(156.564)$ & & $\begin{array}{l}0.235 * * * \\
(171.45)\end{array}$ \\
\hline LnX4 & & & & $-0.02(0.796)$ \\
\hline LnX5 & & $-0.012(0.022)$ & & $0.271 * * *(104.333)$ \\
\hline Cons. & $10.256 * *(26.043)$ & & & $0.967 / 0.945$ \\
\hline $\mathrm{R}^{2} /$ Ad. ${ }^{2}$ & 0.715 & $0.946 / 0.923$ & 0.851 & 0.086 \\
\hline S.D & 0.3753 & 0.165 & 0.272 & 0.000 \\
\hline Prob.>F & 0.000 & 0.000 & 0.000 &
\end{tabular}

*. Significant at $\mathrm{P} \leq 0.05 ; * *$. Significant at $\mathrm{P} \leq 0.01 ; * * *$ Significant at $\mathrm{P} \leq 0.001$.

The model 1 indicates that there exists a significant positive relationship between the aggregate of technology import and the innovation capacity of enterprises; from the outcome of model 2,3 and 4, among the three forms of technology import, the two forms, patent, proprietary technology license and transfer(x2) and the technology consultancy and technology service(x3) both have significant positive effects on the innovation capacity of enterprises, while the joint venture cooperation and equipment purchase(x4) has no such significant effect. At the same time, the import of high-tech products(x5) is introduced to take a robustness test. The outcome indicates that the import of high-tech products(x5) has a significant positive effect on the innovation capacity of enterprises, too. This represents that the technology import has a significant positive effect on the innovation capacity of enterprises.

Model 5-7 test the effect of the absorptive capacity on the innovation performance of high-tech enterprises. The analysis result is shown in table 3. 
Table 3. Ridge regression result (II) ( $\mathrm{Y}=$ innovation capacity)

\begin{tabular}{l|l|l|l}
\hline & M5 & M6 & M7 \\
\hline LnZ1 & $0.911^{* * *(6.546)}$ & & $0.57 * * *(95.822)$ \\
\hline LnZ2 & & $0.791 * * *(5.008)$ & $0.406^{* * *(84.078)}$ \\
\hline Cons. & $10.056^{* * *(32.615)}$ & $6.798^{* * *(5.835)}$ & \\
\hline $\mathrm{R}^{2} /$ Ad. ${ }^{2}$ & $0.830 / 0.818$ & $0.626 / 0.601$ & $0.985 / 0.978$ \\
\hline S.D & 0.29 & 0.4304 & 0.21 \\
\hline Prob.>F & 0.000 & 0.000 & 0.000 \\
\hline
\end{tabular}

*. Significant at $\mathrm{P} \leq 0.05 ; * *$. Significant at $\mathrm{P} \leq 0.01 ; * * *$. Significant at $\mathrm{P} \leq 0.001$.

The outcome of the regression analysis of model 5, 6 and 7 shows that both research outlay input and research staff input of enterprises have significant positive effects on the innovation capacity of enterprises. In other words, the absorptive capacity, represented by the research outlay input and research staff input, has a significant positive effect on the innovation capacity of enterprises.

Finally, this research analyzes the interrelation among the technology import, the absorptive capacity and the innovation performance of high-tech enterprises. The outcome is shown in table 4.

Table 4. Ridge regression result (III) ( $\mathrm{Y}=$ innovation capacity)

\begin{tabular}{|c|c|c|c|}
\hline & M8 & M9 & M10 \\
\hline $\mathrm{LnX} 2$ & $0.159 * * *(224.966)$ & $0.125 * * *(38.99)$ & $0.128 * * *(204.885)$ \\
\hline $\operatorname{LnX} 3$ & $0.151 * * *(92.894)$ & $0.105 * * *(158.36)$ & $0.111 * * *(66.076)$ \\
\hline $\mathrm{LnX} 4$ & $0.081(3.244)$ & & \\
\hline LnX5 & $0.164 * * *(48.262)$ & $0.131 * * *(90.56)$ & $0.130 * * *(73.823)$ \\
\hline $\operatorname{LnZ1}$ & $0.166 * * *(49.343)$ & $0.132 * * *(57.388)$ & \\
\hline LnZ2 & $0.156 * * *(168.60)$ & $0.791 * * *(5.008)$ & $0.127 * * *(144.66)$ \\
\hline $\mathrm{LnX}_{2} \mathrm{LnZ}_{1}$ & & $0.14 * * *(92.912)$ & \\
\hline $\operatorname{LnX}_{3} \operatorname{LnZ}_{1}$ & & $0.132 * * *(21.618)$ & \\
\hline $\mathrm{LnX}_{5} \mathrm{LnZ}_{1}$ & & $0.133 * * *(195.066)$ & \\
\hline $\operatorname{LnX}_{2} \operatorname{LnZ}_{2}$ & & & $0.13 * *(5.425)$ \\
\hline $\mathrm{LnX}_{3} \operatorname{LnZ}_{2}$ & & & $0.122 * * *(57.44)$ \\
\hline $\mathrm{LnX}_{5} \mathrm{LnZ}_{2}$ & & & $0.128 * * *(107.725)$ \\
\hline $\mathrm{R}^{2} / \mathrm{Ad} \cdot \mathrm{R}^{2}$ & $0.975 / 0.895$ & $0.987 / 0.956$ & $0.975 / 0.856$ \\
\hline S.D & 0.05 & 0.026 & 0.042 \\
\hline Prob.>F & 0.050 & 0.003 & 0.108 \\
\hline
\end{tabular}

*. Significant at $\mathrm{P} \leq 0.05 ; * *$. Significant at $\mathrm{P} \leq 0.01 ; * * *$. Significant at $\mathrm{P} \leq 0.001$.

The outcome of the analysis of the model 8, all the variables, except the joint venture cooperation and equipment purchase $(\mathrm{x} 4)$, have significant positive effects on the innovation capacity of enterprises.

The model 9 analyzes the interaction between the research outlay input and technology import, and the effect of research outlay input on the innovation capacity. Because the joint venture cooperation and equipment purchase $(\mathrm{x} 4)$ has been examined not to behave a significant relationship before, it is eliminated this time. From the outcome of analysis, there exists a significant positive interaction between the research outlay input and the technology import, and the research outlay input has a significant influence on the innovation capacity of enterprises. According to the outcome, the research outlay inputzl has significant positive interactions with $\mathrm{x} 2, \mathrm{x} 3$, and $\mathrm{x} 5$, which means that the absorptive capacity could help 
enterprises to absorb the outcome of technology import and promote their innovation capacity better.

The model 10 analyzes the interaction between the research staff input and the technology import and the effect of research staff input on the innovation capacity. Also, in the model 10, because the joint venture cooperation and equipment purchase $(\mathrm{x} 4)$ has been examined not to behave a significant relationship before, it is eliminated this time. According to the outcome of analysis, there is a significant positive interaction between the research staff input and the technology import, and the research staff input has a significant effect on the innovation capacity of enterprises, but the validity of the whole model is not significant. According to the outcome, the research staff input $\mathrm{z} 2$ has significant positive interactions with $\mathrm{x} 2, \mathrm{x} 3$, and $\mathrm{x} 5$, which means that the absorptive capacity could help enterprises to absorb the outcome of technology import and promote their innovation capacity better.

In conclusion, the hypothesis 3 is supported. The effect of technology import on the independent research capacity of high-tech enterprises is significantly positively affected by their absorptive capacity.

\section{Conclusion}

According to the comprehensive outcome of empirical analysis, several conclusions are given as follows.

Firstly, the outcome of the research shows that there is a significant positive relationship between the technology import and the innovation capacity, particularly the three forms of technology import: technology import, patent consultancy and services, and the high-tech products import. While the joint venture cooperation and equipment purchase have no such significant effect. This indicates that the joint venture cooperation and equipment purchase are all ways of enjoying foreign countries' existed technology, but not focusing on the cultivation of the absorptive capacity, which cannot improve the innovation capacity of China's enterprises.

Secondly, the high-tech products import has a significant positive effect on the innovation capacity. Compared to the joint venture cooperation and the equipment purchase, maybe because the technology in the high-tech products introduced is easier to be assimilated, absorbed, or mimed, it can promote the innovation of enterprises better.

Thirdly, the research outlay input has a significant positive interaction with the technology import and the high-tech products import, which means that the research outlay inputted by enterprises can promote the effects of the technology import and their innovation capacity.

Finally, the research staff input also has a significant positive interaction with the technology import and the high-tech products import, but is not as significant as the research outlay input, which means that the heat source efficiency of the science and technology research and development of China's high-tech enterprises is still waited to be enhanced.

The result of this research indicates that enterprises are supposed to improve their absorptive capacity during the introducing of technology, which can make twofold results with half the effort.

\section{Acknowledgement}

This research was financially supported by the SSF of Guangdong Province (No.2015A070704013; 2015A070704006); Philosophy and social science project of Guangdong Province (GD15CYJ15); and Northwest A\&F University (Research on the 
innovation ability's evaluation and promotion mechanism of the innovative enterprises in Shaanxi Province; 2013RWYB03).

\section{References}

[1] Kim L. \& Nelson R. Technology, Learning, and Innovation: Experience of Newly Industrialized Economic[M]. Cambridge: Cambridge University Press(2000).

[2] M. Christensen \& Michael E. Raynor. The Innovator's Solution: Creating and Sustaining Successful Growth by Clayton. [J]. Harvard Business School Publishing Corporation(2003).

[3] Robert Burgelamn. Strategic Management of Technology and Innovation[M]. McGraw-hill, (2004):158-162.

[4] Turban, E., R. Rainer and R. Poter (2003). Introduction to Information Technology. Hoboken, NJ, John Wiley \& Sons, Inc.

[5] Lin Yifu, Zhang Pengfei. Appropriate technology, technology choice and economic growth in developing countries (J), Economics, 2006 (5): 985-1005.(In Chinese)

[6]Zhu Guilong, Zhou Quan. Research on the enterprise technology innovation strategy selection mechanism and model [J]. science and technology management research, 2006, 3:51-53. .(In Chinese)

[7] Liu Zhongli, Huang Pingchuan. Research on the influence of technology import on technological innovation ability of enterprises in China - based on quantile regression of China provincial data, Nankai economic studies, [J]. 2011:(5): 132-141. .(In Chinese)

[8] Liu Junjie, Fu Yuwei. Analy Philosophy and social science project of Guangdong Province Philosophy and social science project of Guangdong Provincesis of factors affecting the independent innovation environment of high-tech enterprises [J]. academic community, 2009, 1:198-202. .(In Chinese)

[9] Cohen, W. and D. Levinthal(1990). "Absorptive capacity: a new perspective on learning and innovation." Administrative Science Quarterly 35: 128-152.Dell, C. O. and C. J. Grayson (1998). If Only We Knew What We Know: The Transfer of Internal Knowledge and Best Practice. New York, Free Press.

[10] Daghfous, A. Absorptive Capacity and the Implementation of Knowledge-Intensive Best Practices. S.A.M. Advanced Management Journal 2004 69(2): 21-27.

[11] Nemanich, L. A. The strategic impact of absorptive capacity on technological innovation: A multi-dimensional, multi-method analysis. 3194349 Ph.D.,2005 University of Houston.

[12]Ding Shuheng. Path selection: theoretical and empirical research on the [J]. industry technology economy, 2005 (4): 61-70. .(In Chinese)

[13] Yuan Jianhong, Wang Jingjing. The cognitive study of Enterprise Independent Innovation -- Based on the innovative case analysis of two enterprises [J]. technology progress and countermeasure, 2010,27 (12): 94-96. .(In Chinese)

[14] Song Baolin, LiZhaoyou. Research on technological innovation technological knowledge flow in the process of technological knowledge flow [J]. technological progress and countermeasure, 2010,27 (16): 156-160. .(In Chinese) 